\title{
Rating scales validated for Sri Lankan populations: an update
}

\author{
CU Suraweera, DP Yasira, V de Silva, R Hanwella, J Galhenage, IC Perera
}

\section{Abstract}

Rating scales are widely used in psychiatric practice to screen, diagnose, monitor symptoms, and for research purposes. Most scales utilized in psychiatry have been formulated in the West. Many rating scales are limited with regards to local use, as they have not been culturally adapted and validated to the Sri Lankan setting. We searched all relevant publications in journals indexed in PubMed, Scopus, and Google Scholar and dissertations in the Registry of Post
Graduate Institute of Medicine, University of Colombo to identify relevant articles containing details on validation and adaption of rating scales for the Sri Lankan setting. We identified 31 scales validated for use in Sri Lanka.

Keywords: validation, adaption, rating scales, Sinhala, Tamil

SL J Psychiatry 2020; 11(2): 4-12

\section{Introduction}

In psychiatry, rating scales are used widely for many purposes - to screen, diagnose, and monitor for symptoms, and for research purposes. Most scales used in the field of psychiatry have been formulated in the West. However local use of these scales can be limited, since they have not been culturally adapted and validated to the Sri Lankan setting. With the increased use of rating scales in current day to day practice, the need to culturally adapt and validate rating scales have increased. Increasing research in the field of psychiatry may also have contributed to the increased need for validation of existing scales for the Sri Lankan setting. Our article 'Rating scales validated for Sri Lankan Populations' published in 2013 was an attempt to fill this void (1). The objective of this article is to update our previous article, by examining for rating scales adapted and/or validated for the Sri Lankan population from 2013 to 2020, in the Sinhala and Tamil languages.

\section{Methodology}

Similar to the methodology used in the previous article, we searched PubMed, Scopus, and Google scholar using the keywords; validation, rating scales, Sinhala, Tamil, Sri Lanka, validity, reliability, psychometric properties (1). All relevant publications in journals indexed in PubMed, Scopus, and Google Scholar were identified and included in the article. The registry of dissertations at the Postgraduate Institute of Medicine (PGIM), University of Colombo, Sri Lanka was also utilized to obtain details on research conducted regarding validation and adaptation of rating scales to the Sri Lankan population. We have also included tools validated in Tamil in India, as they too can be used in the Sri Lankan setting. Scales that have been translated but not validated are indicated specifically. Scales that have been validated but not published in a journal indexed have not been included in this article. Conference abstracts and dissertations published by institutions other than the PGIM were not included in the article.

\section{Results}

\section{Scales used to identify depression and anxiety}

\section{Centre for Epidemiological Studies Depression Scale (CES-D)}

The Center for Epidemiologic Studies Depression Scale (CES-D) is a 20-item, self-report instrument that is widely used to measure depressive symptoms in the general population (2). The CES-D has been validated in Sinhala to diagnose depression in out-patient settings (3). The proposed cut-off score for the Sinhala version of the CES-D is $\geq 16$ as it gives a sensitivity of $84 \%$ and specificity of $92 \%$. 


\section{Beck Depression Inventory-II (BDI II)}

The BDI-II assesses the presence and severity of depressive symptoms (4). It is a 21-item self-report instrument that attempts to detect depressive symptoms according to diagnostic criteria listed in the Diagnostic and Statistical Manual for Mental Disorders 5th edition (DSM 5). Items are summed to create a total score, with higher scores indicating higher levels of depression. Beck et al. in their study suggested a score of 14 or greater as indicative of at least mild depression. In the validation study conducted in Sri Lanka by Rodrigo et al., a cut-off of 16 was selected as having optimal sensitivity and specificity (5).

\section{Short-form Geriatric Depression Scale-15 (GDS-15)}

The Geriatric Depression Scale (GDS-15) is a self-rated depression screening instrument that has 15 items (6). The Tamil validation study of GDS -15 has been conducted in a rural population in Tamil Nadu and a score of 8 and above was chosen as the cut-off for depression (7). The sensitivity of this score was $80 \%$, though specificity was somewhat lower at $47.6 \%$. The Sinhala validation of GDS-15 was done in 2010 by Kulathunga et al. (8).

\section{Calgary Depression Scale for Schizophrenia (CDSS)}

The Calgary Depression Scale for Schizophrenia (CDSS) is a simple rating scale that can be easily administered in a busy clinical setting. It is one of the most effective screening tools to detect depression in schizophrenia, when compared to a variety of other depression screening tools (9). The CDSS was validated for a Sinhala speaking population in a study conducted among patients with schizophrenia. The optimal cut-off value for the CDSS was 6 with a sensitivity of $93.25 \%$ and a specificity of $97.83 \%(10)$.

\section{Hopkins Symptoms Checklist (HSCL-25)}

The Hopkins Symptoms Checklist (HSCL) is a 25-item screening instrument that measures symptoms of anxiety and depression (11). It consists of 25 items, where part I has 10 items for anxiety and part II has 15 items for depression. The total score has been shown to correlate highly with severe emotional distress of unspecified diagnosis, and the depression score with major depression as defined by the Diagnostic and Statistical Manual of the American Psychiatric Association, IV Version (DSM-IV). The HSCL-25 has been validated to Sinhala by Jayasuriya et al (12). The Tamil translation of the scale has been used in a study conducted in Jaffna, Sri Lanka (13).

\section{Liebowitz Social Anxiety Scale (LSAS-SR)}

The self-report version of the Liebowitz Social Anxiety Scale (LSAS-SR) screens for social anxiety disorder (14). It consists of 24 items each on two subscales on fear and avoidance. A total score of 39 , which had a sensitivity of $82.1 \%$ and specificity of $79.6 \%$ was chosen as the optimal cut-off score in the validation study in Sinhala, conducted in Sri Lanka (15).

\section{Perinatal Anxiety Screening Scale (PASS)}

The Perinatal Anxiety Screening Scale (PASS) is used to screen for a broad range of anxiety symptoms during the pregnancy and the postpartum period (16). It is a 31-item questionnaire that assesses for anxiety in four categories: acute anxiety and adjustment, general worry and specific fears, perfectionism, control, and trauma and social anxiety. The optimal cut-off point for the PASS validated to the Sinhala population is $\geq 20$ (17).

\section{Obsessive-Compulsive Inventory-Revised Scale (OCI-R)}

The Obsessive-Compulsive Inventory-Revised Scale (OCI-R) is derived from the original ObsessiveCompulsive Inventory (OCI) (18). It is an 18-item tool that measures obsessive compulsive symptoms using six subscales. The OCI-R has been culturally adapted and validated for the Sri Lankan setting and the cut off value for the validated Sinhala version is 21 (19).

\section{Scales used to identify cognitive dysfunction}

\section{Repeatable Battery for the Assessment of Neuropsychological Status (RBANS)}

The Repeatable Battery for the Assessment of Neuropsychological Status (RBANS) is a battery to assess neurological status, which can be used amongst subjects aged 12-89 years. The RBANS has 6 index scores, which includes a total scale index and five domainspecific index scores that assess immediate memory, visuospatial/constructional abilities, language, attention, and delayed memory (20). The RBANS can be used to measure the cognitive profiles in a range of disease conditions such as dementia and schizophrenia. It can also be used to measure cognitive profiles of the normal population, which is an added advantage. The RBANS has been culturally adapted and validated to Sinhala and used to measure the cognitive status of normal adults (21). The Tamil translation of RBANS is available.

\section{Rey Auditory Verbal Learning Test (RAVLT)}

The RAVLT is used to evaluate short-term auditoryverbal memory, rate of learning, learning strategies, retroactive, and proactive interference, presence of confabulation of confusion in memory processes, 
retention of information, and differences between learning and retrieval (22). The tool was validated for the Sri Lankan population aged 19-83 years by Dassanayake et al. thereby allowing the tool to be used in the Sri Lankan setting (23).

\section{Montreal Cognitive Assessment Scale (MoCA)}

The MoCA (Montreal Cognitive Assessment) is one of the most commonly used cognitive assessment tools, particularly in screening for mild cognitive impairment and early dementia (24). The MOCA has been culturally adapted and validated to the Sinhala speaking population (25). Unlike the usual cut-off of 26, the cut-off for the Tamil version has been defined at 24 , as this yielded the best balance between sensitivity and specificity (26).

\section{Addenbrooke's Cognitive Examination-Revised (ACE-R)}

The Addenbrooke's Cognitive Examination-Revised (ACE-R) is a battery to assess cognitive functions, in order to detect and classify different kinds of dementia (27). It contains 5 subtests: attention/orientation (18 points), memory (26 points), fluency (14 points), language (26 points) and visuospatial (16 points) (27). The cutoff score for detecting dementia in the ACE-R validated for the Sinhala speaking population aged $\geq 50$ years is 80 , with a sensitivity of $91.9 \%$ and specificity of $76.3 \%$ (28).

\section{Scales used in children and adolescents Bayley Scales of Infant Development}

The Bayley Scales of Infant Development is a psychometric tool for assessing the development of children between 1 to 42 months of age (29). It is a valid diagnostic tool for identifying developmental delays in children at an early age. The Bayley III (BSITD III) which is currently the third edition, assesses infant and toddler development in five developmental domains, namely: cognition, language, social-emotional, motor, and adaptive behaviour (30). One of the major limitations in using the BSITD III in the past was that the Bayley scores are based on norms established for children in the United States. The validation study to Sri Lanka conducted by Godamunne et al. observed some differences between the performance of children in the United States and Sri Lanka, with regards to the motor and cognitive scales (31). However, the differences showed no consistent agerelated pattern.

Adolescent Suicide Assessment Protocol-20 (ASAP-20) The Adolescent Suicide Assessment Protocol-20 (ASAP20) is a twenty-item brief, user-friendly, structured clinical interview that can be used to categorize the risk of suicide among adolescents (32). The ASAP-20 is organized into four domains: Historical, Clinical, Contextual, and
Protective. The cut-off value for the scale which was validated and culturally adapted to Sinhala is 8.5 , which has a sensitivity of $91 \%$ and a specificity of $91 \%$ (33).

\section{Pictorial Autism Assessment Schedule (PASS)}

The Pictorial Autism Assessment Schedule (PASS) was developed by Perera et al. based on items adopted from several sources, so that the scale can be administered in the Sri Lankan setting (34). The main source was the diagnostic criteria for autism spectrum disorder in the DSM 5 (35). The other items were selected from the Modified Autism Checklist for Toddlers (M-CHAT) and "First Signs" from the American Academy of Neurology and the Child Neurology Society (36) (37). The tool can be used in children aged 18-48 months. The PASS was validated in both Sinhala and Tamil.

\section{Sri Lankan Early Teenagers' Violence Inventory (SLETVI)}

The Sri Lankan Early Teenagers’ Violence Inventory (SLETVI) was developed in Sri Lanka as a self-report questionnaire. The scale assesses victimization and perpetration of peer violence among adolescents of 13-15 years of age (38). SLETVI can be used to identify a range of violent acts in three categories; namely, less severe violence, severe physical violence, and severe relational violence. The scale is not only validated and culturally adapted but developed in Sri Lanka.

\section{Parent/Teacher Disruptive Behaviour Rating Scale (P/T DBD Rating scale)}

The Parent/Teacher Disruptive Behaviour Rating Scale (P/T DBD Rating scale) is a screening tool designed to support the diagnosis of externalizing disorders (39). The DBD rating scale consists of 42 items related to symptoms of Conduct disorder (16 items), ODD (8 items), ADHDInattention (9 items), ADHD- hyperactivity/ Impulsivity (9 items) (39). The scale has been validated among the Sinhala speaking adolescents aged $11-17$ years (40).

\section{Student Questionnaire (SQ)}

The Student Questionnaire (SQ) has demonstrated good validity and reliability in detecting the prevalence and pattern of substance use among adolescents $(41,42)$. The SQ has several sections: introduction, background, demographic characteristics, use of cigarettes and alcohol, familiarity with and the use of various controlled substances, age at first use, personal disapproval of use, perceived risk of using, and perceived availability of substances. The SQ adapted to Sinhala is titled Adolescent Substance Use Student Questionnaire (ASUSQ) and the validation has been conducted among 13-18-year-old Sri Lankan adolescents attending school (43). 


\section{TNO-AZL Preschool children Quality of Life} (TAPQOL)

The Netherlands Organization for Applied Scientific Research Academic Medical Centre (TNO-AZL) Preschool children Quality of Life (TAPQOL) is a scale that consists of 43 items grouped into 12 subscales (44). The subscales are groups of items describing different aspects of the quality of life of a child, representing the domains of health, physical, emotional, cognitive, and social health. The Sinhala version of the questionnaire has 44 items arranged in twelve subscales and the validation study has been conducted among children in the age group of 3 to 4 years in the Colombo District (45).

\section{Scales used to identify trauma}

\section{Ispcan Child Abuse Screening Tool-Retro- spective Version (ICAST-R)}

The Ispcan Child Abuse Screening Tool-Retrospective Version (ICAST-R) has been developed by the International Society for the Prevention of Child Abuse and Neglect (ISPCAN) of the World Health Organization (WHO) (46). The ICAST-R retrospectively assesses abusive experiences during childhood in young adults aged 18-24 years. The questions focus on physical, sexual, and emotional maltreatment by adults or peers. The validation study for Sri Lanka has been conducted among school-going young adults between the ages of 18-20 years in selected educational zones in the Kalutara district, Western Province (47).

\section{Harvard Trauma Questionnaire (HTQ)}

The Harvard Trauma Questionnaire (HTQ) is one of the most widely used screening tools to detect post-traumatic stress disorder (PTSD) (48). It has been used among refugees and in post-conflict fields. Multigroup Confirmatory Factor Analysis (MG-CFA) to test the fourfactor (DSM-5 consistent) and three-factor (DSM-IV-TR) models of PTSD, and assessment of measurement invariance of the four-factor model by gender and ethnic groups has been carried out in Sri Lanka by Jayasuriya et al. The translation and validation of modified HTQ to Sinhala was done as a part of this study (49). The 24-item Tamil HTQ has been validated in a study conducted among Sri Lankan Tamil refugees in India and Canada (50).

\section{Scales used to identify the degree of pain Pain catastrophizing scale (PCS)}

The Pain Catastrophizing Scale (PCS) evaluates pain catastrophizing as a single construct with three components namely, rumination, magnification, and helplessness (51). It includes 13 items with a total score ranging from 0 to 52. The Cronbach's alpha values of the three components and total scores for patients and healthy adults in the validation study to Sinhala have ranged from 0.72 to 0.87 (52).

\section{Short-Form McGill Pain Questionnaire-2 (SF MPQ-2)}

ThenShort-Form McGill Pain Questionnaire-2 (SF MPQ2 ) is one of the widely used multidimensional pain scales and contains 22 pain descriptors with four subscales: one affective and three sensory (53). The Sinhala Version of Short-Form McGill Pain Questionnaire-2 has been validated to Sri Lanka among patients with pain due to cancer (54). The Cronbach's alpha coefficients computed for each subscale ranged from 0.76 to 0.82 in the study (54).

\section{Scales used to identify issues regarding sleep Pittsburgh Sleep Quality Index (PSQI)}

The Pittsburgh Sleep Quality Index (PSQI) is a commonly used rating scale to assess sleep quality (55). It measures the quality of sleep of a person in the previous month. The PSQI consists of 19 self-rated questions that are scored to obtain a total score. The 19 items are grouped into seven components which are added to give the total score. The scores can range from 0 to 21 . Higher scores on the PSQI scale indicate poor sleep quality. The tool has been validated for Sri Lankan population by Anandakumar et al. and is available in Sinhala (56).

\section{Epworth Sleepiness Scale (ESS)}

The Epworth Sleepiness Scale (ESS) is used widely in research and clinical settings to assess daytime sleepiness (57). The scale is an eight-item questionnaire with responses on a four-point Likert scale, with scores ranging from zero to three. The scale has been validated to Tamil in a study conducted among adolescents in the age group of 10-19 years in South India (58). The study yielded a reliability coefficient (Cronbach's alpha) of 0.81 for ESS (58).

\section{Scales used to identify miscellaneous conditions}

\section{World Health Organization-5 (WHO-5)}

The World Health Organization-5 (WHO-5) comprises of the positively phrased items of WHO -10 and measures the positive well-being reflecting mental health (59). The scale has been validated to the Sinhala speaking population in a study conducted on persons aged 16-75 years in a semi-urban area of Sri Lanka (60).

\section{World Health Organization Disability Assessment Schedule 2.0 (WHO DAS 2.0-36)}

The 36 item interviewer-administered proxy version of the World Health Organization Disability Assessment Schedule 2.0 (WHO DAS 2.0-36) is a generic assessment instrument for health and disability which can be used in 
all diseases, including mental, neurological, and addictive disorders (61). It is short, simple, and easy to administer, requiring about 5 to 20 minutes and is applicable in both clinical and general population settings. The WHO DAS 2.0-36 has been validated to Sinhala among the caregivers of individuals with schizophrenia in Sri Lanka. The abstract of the presentation has been published in the supplementary issue of the Journal of College of Community Physicians of Sri Lanka (62).

\section{Patient Practitioner Orientation Scale (PPOS)}

The Patient Practitioner Orientation Scale (PPOS) is a self-administered tool that assesses patient centeredness along with caring and sharing dimensions among healthcare professionals and patients (63). The scale comprises of 18 Likert items, of which nine evaluate caring attitudes and the rest evaluate sharing attitude. The validation of the scale to the Sri Lankan setting in Sinhala has included 543 medical students, 67 doctors, 335 allied health students, and 422 patients (64). The Cronbach's alpha for these groups ranged from 0.48 to 0.53 for sharing, 0.42 to 0.53 for caring, and 0.62 to 0.65 for the total score (64).

\section{Maslach Burnout Inventory-Human Services Survey (MBI-HSS)}

The Maslach Burnout Inventory (MBI) has been extensively used to measure burnout among people who are working in human services (65). With the development of alternate forms of the MBI for educators and professions other than human services, the original MBI has been renamed as the Maslach Burnout Inventory Human Services Survey (MBI-HSS). The MBI-HSS consists of 22 items to assess the three dimensions of burnout. Nine items evaluate emotional exhaustion, while depersonalization and personal accomplishment are assessed by five and eight items. The scale has been validated to Sinhala and used to determine the burnout among prison officers (65).

\section{The Health Promoting Lifestyle Profile-II (HPLP-II)}

The Health Promoting Lifestyle Profile-II (HPLP-II) is the revised version of the HPLP developed by Walker et al (66). It measures health-promoting lifestyles by focusing on self-initiated actions and perceptions that serve to maintain or enhance the level of wellness, self- actualization, and fulfillment of the individual. It is a 52-item questionnaire comprising of six subscales: health responsibility, nutrition, physical activity, stress management, interpersonal relations, and spiritual growth (66). The scale has been validated to the Sinhala language and was used in a study conducted on postmenopausal women (67).

\section{Morisky Medication Adherence Scale (MMAS-8)}

Morisky Medication Adherence Scale (MMAS-8) is a self-report scale used in assessing medication adherence in patients on chronic therapy (68). The eight-item scale includes questions to assess forgetfulness, symptom severity, and situational and emotional aspects of medication adherence. The scale has been validated for the Sinhala speaking population in a validation study conducted on patients with a bipolar affective disorder on lithium therapy (69).

\section{Genos Emotional Intelligence Inventory (Genos EI)}

The Genos Emotional Intelligence Inventory (Genos EI) is a behaviour-based measurement that provides insight into how well an individual demonstrates emotionally intelligent workplace behaviours across seven dimensions (70). The Sinhala version of Genes EI has been validated among medical students of Sri Lanka and was found to have a reliability of 0.89 (71).

\section{Sexual Inhibition and Sexual Excitation Scales (SIS/SES)}

Sexual Inhibition and Sexual Excitation Scales (SIS/SES scales) were developed to measure individual propensities for sexual excitation and sexual inhibition (72). The questionnaire is comprised of 45 items with three subscales: one for sexual excitation and two for sexual inhibition. The scales have been validated to five languages commonly used by South Asians living in the UK namely: Hindi, Urdu, Panjabi, Tamil, and Sinhala (73).

\section{Medical Students' Stressor Questionnaire (MSSQ)}

The Medical Students’ Stressor Questionnaire (MSSQ) is a tool that assesses the degree of stress among medical students (74). It is a self-reported and self-scoring instrument with 40 items where the students rate the intensity of stress on a scale of 0-4 in each item. The scale adapted and validated to Sinhala had an overall Cronbach' s alpha of 0.95 and values ranging from 0.54 to 0.90 for the subscales (75). The scale has been validated to Tamil among medical students in India (76).

\section{Discussion}

We identified 36 scales that have been culturally adapted and/or validated to the Sri Lankan setting and published from 2013 to 2020. Three scales were validated to Tamil in India, which we have included as they can be used in the Sri Lankan setting (7)(50)(58). Two scales were not 
published and were retrieved from the registry of dissertations of the PGIM (40). Two studies yielded normative data for the Sri Lankan setting (23) (31). Two scales were developed in Sri Lanka (34) (38). The RBANS has been translated to Tamil with no validation.

We observed that a significant number of scales have been validated to the Sri Lankan setting during the study period. This implies that the researchers are increasingly recognizing the importance of using rating scales validated to the Sri Lankan setting. In several instances, the given rating scale has been validated as a part of a more comprehensive study, which required the use of that particular rating scale validated to Sinhala or Tamil. Requests by various ethics review committees for the use of culturally adapted and validated rating scales may have contributed to the increased number of studies using culturally adapted and validated rating scales.

\section{Limitations}

We have not included any validation studies published in the grey literature, which may be a limitation. Although rating scales validated to Tamil in India are mentioned in the study, the degree of cultural adaption of such scales to the Sri Lankan setting is questionable. The same limitation may apply to scales validated among Sinhala and Tamil speaking Sri Lankans living in other countries. Despite validation to the Sri Lankan setting, the use of some rating scales is limited by copyright issues.

\section{Conclusions}

More scales need to be adapted and validated for use in the Sri Lankan setting in the future. This will improve the validity of findings and allow local research to be compared with other countries more reliably. More research should be undertaken to develop rating scales in Sri Lanka, such as the Pictorial Autism Assessment Schedule, the Peradeniya Depression Scale and the Sri Lankan Early Teenagers’ Violence Inventory (77), (19), (38).

\section{Statement of contribution}

All authors contributed equally in literature survey and writing the manuscript.

\section{Conflicts of interest}

None declared.
CU Suraweera, V de Silva, R Hanwella, Department of Psychiatry, University of Colombo, Sri Lanka

DP Yasira, District General Hospital, Embilipitiya, Sri Lanka

J Galhenage, IC Perera University Psychiatry Unit, National Hospital of Sri Lanka

Corresponding author: CU Suraweera

Email: dr.chathurie@gmail.com

D http://orcid.org/0000-0002-7542-506

\section{References}

1. Suraweera C, Hanwella R, Sivayokan S, De Silva V. Rating Scales validated for Sri Lankan populations. Sri Lanka J Psychiatry. 2013; 4(2): 16.

2. Radloff LS. The CES-D Scale: A Self-Report Depression Scale for Research in the General Population. Appl Psychol Meas. 1977; 1(3): 385-401.

3. de Silva VA, Ekanayake S, Hanwella R. Validity of the Sinhala version of the centre for epidemiological studies depression scale (CES-D) in out-patients. Ceylon Med J. 2014; 59(1): 8-12.

4. Steer RA, Clark DA, Beck AT, Ranieri WF. Common and specific dimensions of self-reported anxiety and depression: The BDI-II versus the BDI-IA. Behav Res Ther. 1999; 37(2): 183-90.

5. Rodrigo A, Kuruppuarachchi KALA, Pathmeswaran A. Validation of the Beck Depression Inventory II among the Sinhalese speaking population in Sri Lanka. Sri Lanka J Psychiatry. 2015; 6(2): 20.

6. Yesavage JA, Brink TL, Rose TL, Lum O, Huang V, Adey $\mathrm{M}$, et al. Development and validation of a geriatric depression screening scale: A preliminary report. J Psychiatr Res. 1982; 17(1): 37-49.

7. Sarkar S, Kattimani S, Roy G, Premarajan KC, Sarkar S. Validation of the Tamil version of short form Geriatric Depression Scale-15. J Neurosci Rural Pract. 2015; 6(3): 442-6.

8. Kulathunga M, Umayal S, Somaratne S, Srikanth S, Kathriarachchi S, Krd DS. Validation of the Geriatric Depression Scale for an elderly Sri Lankan clinic population. Indian J Psychiatry [Internet]. 2010; 52(3): 254-6. Available from: http://ovidsp.ovid.com/ ovidweb.cgi ? T = J S \& PA GE =reference $\& D=$ emed12\&NEWS=N\&AN=70212205

9. Addington D, Addington J, Atkinson M. A psychometric comparison of the Calgary Depression Scale for Schizophrenia and the Hamilton Depression Rating Scale. Schizophr Res. 1996; 19(2-3): 205-12. 
10. Yasira P. Validation of Calgary Depression Scale for Schizophrenia-Sinhala version (CDSS-S) in a Sri Lankan population and evaluation of prevalence of major depressive episode (MDE) in patients with schizophrenia at university psychiatry unit of the National Hospit. Available from: http://librepository.pgim.cmb.ac.lk

11. Parloff MB, Kelman HC FJ. Comfort, effectiveness, and self-awareness as criteria for improvement in psychotherapy. 1954; 3: 343-. Am J Psychiatry 1954; 3: 343-51.

12. Tay AK, Jayasuriya R, Jayasuriya D, Silove D. Measurement invariance of the Hopkins Symptoms Checklist: A novel multigroup alignment analytic approach to a large epidemiological sample across eight conflict-affected districts from a nation-wide survey in Sri Lanka Andrew Rasmussen, Nuwan Jayawickreme. Confl Health. 2017; 11(1).

13. Husain F, Anderson M, Lopes Cardozo B, Becknell K, Blanton C, Araki D, et al. Prevalence of war-related mental health conditions and association with displacement status in postwar Jaffna District, Sri Lanka. JAMA - J Am Med Assoc. 2011; 306(5): 522-31.

14. Heimberg RG, Horner KJ, Juster HR, Safren SA, Brown EJ, Schneier FR, et al. Psychometric properties of the Liebowitz Social Anxiety Scale. Psychol Med. 1999; 29(1): 199-212.

15. Hapangama A, Kuruppuarachch LA, De Silva R, Wickremasinghe AR, Ravindran A, Williams SS. Crosscultural adaptation and validation of the Leibowitz Social Anxiety Scale (LSAS-SR) Sinhala Version. Ceylon Med J. 2020; 65(1-2): 28.

16. Somerville S, Dedman K, Hagan R, Oxnam E, Wettinger M, Byrne S, et al. The Perinatal Anxiety Screening Scale: development and preliminary validation. Arch Womens Ment Health. 2014; 17(5): 443-54.

17. Priyadarshanie MN, Waas MDIA, Goonewardena CSE, Balasuriya A, Senaratna BCV, Fernando DMS. Sinhala translation of the Perinatal Anxiety Screening Scale: A valid and reliable tool to detect anxiety disorders among antenatal women. BMC Psychiatry. 2020; 20(1).

18. Foa EB, Kozak MJ, Salkovskis PM, Coles ME, Amir N. The validation of a new obsessive-compulsive Inventory. Psychol Assess [Internet]. 1998; 10(September): 206-21. Available from: http://www.aicepsych.com/uploads/4/3/ 7/6/43769695/oci_validity.pdf

19. Senanayake B, Rajasuriya M, Suraweera C, Arambepola C. How valid is obsessive-compulsive inventory-revised scale among Sri Lankan adults? Indian J Psychiatry. 2018; 60(3): 318-23.

20. Randolph C, Tierney MC, Mohr E, Chase TN. The Repeatable Battery for the Assessment of Neuropsychological Status (RBANS): Preliminary clinical validity. J Clin Exp Neuropsychol. 1998; 20(3): 310-9.

21. Suraweera CU, Anandakumar D, Dahanayake D, Subendran M, Perera UT, Hanwella R, et al. Validation of the Sinhala version of the Repeatable Battery for Assessment of Neuropsychological Status (RBANS). Ceylon Med J. 2016; 61(4): 167.
22. Rey A. L'examen psychologique dans le cas d'encephalopathie traumatique. Arch Psychol (Geneve). 1941; 28 : 286-340.

23. Dassanayake TL, Hewawasam C, Baminiwatta A, Samarasekara N, Ariyasinghe DI. Sex-, age- and educationadjusted norms for the WHO/UCLA version of the Rey Auditory Verbal Learning Test for Sinhala-speaking Sri Lankan adults. Clin Neuropsychol. 2020;

24. Nasreddine ZS, Phillips NA, Bédirian V, Charbonneau S, Whitehead V, Collin I, et al. The Montreal Cognitive Assessment, MoCA: A brief screening tool for mild cognitive impairment. J Am Geriatr Soc. 2005; 53(4): 695-9.

25. Karunaratne S, Hanwella R, de Silva V. Validation of the Sinhala version of the Montreal Cognitive Assessment in screening for dementia. Ceylon Med J. 2011;

26. Coonghe PAD, Fonseka P, Sivayokan S, Kesavaraja A, Malhotra R, Ostbye T. Adaptation and validation of the Tamil (Sri Lanka) version of the montreal cognitive assessment. Kesmas. 2020; 15(2): 86-91.

27. Mioshi E, Dawson K, Mitchell J, Arnold R, Hodges JR. The Addenbrooke's Cognitive Examination revised (ACE$\mathrm{R})$ : A brief cognitive test battery for dementia screening. Int J Geriatr Psychiatry. 2006; 21(11): 1078-85.

28. Suriyakumara V, Srikanth S, Wijeyekoon R, Gunasekara $\mathrm{H}$, Muthukuda C, Rajapaksha D, et al. Validation of the Sinhala Version of the Addenbrooke's Cognitive Examination-Revised for the Detection of Dementia in Sri Lanka: Comparison with the Mini-Mental Status Examination and the Montreal Cognitive Assessment. Dement Geriatr Cogn Disord. 2019; 47(4-6): 198-208.

29. Lo R, Nagtegaal M, MacKay M. Levels of agreement between the bayley scales of infant and toddler development, third edition, and other standardized developmental assessments for high-risk preterm infants [Internet]. Vol. 51, Developmental Medicine and Child Neurology. 2009. p. 46. Available from: http:// ovidsp.ovid.com/ovidweb.cgi? T =JS\&PAGE= reference $\& D=$ emed12\&NEWS $=$ N\&AN=70212205

30. Lo R, Nagtegaal M, MacKay M. Levels of agreement between the bayley scales of infant and toddler development, third edition, and other standardized developmental assessments for high-risk preterm infants. Dev Med Child Neurol. 2009;

31. Godamunne P, Liyanage C, Wimaladharmasooriya N, Pathmeswaran A, Wickremasinghe AR, Patterson C, et al. Comparison of performance of Sri Lankan and US children on cognitive and motor scales of the Bayley scales of infant development. BMC Res Notes. 2014; 7(1).

32. Fremouw WJ, Ph D, Strunk JM, Elizabeth A, Musick R, Lcsw MSW. Adolescent Suicide Assessment Protocol20. 2009; (2003).

33. Malalagama AS, Tennakoon S, Abeyasinghe DRR. Validation of Adolescent Suicide Assessment Protocol-20 (ASAP-20) to Sri Lankan adolescents. Asian J Psychiatr. 2018; 33: 11-7.

34. Perera H, Jeewandara KC, Seneviratne S, Guruge C. Culturally adapted pictorial screening tool for autism 
spectrum disorder: A new approach. World J Clin Pediatr. 2017; 6(1): 45.

35. Association AP. Cautionary Statement for Forensic Use of DSM-5. In: Diagnostic and Statistical Manual of Mental Disorders, 5th Edition. 2014. p. 991.

36. McPheeters ML, Weitlauf A, Vehorn A, Taylor C, Sathe NA, Krishnaswami S, et al. Screening for Autism Spectrum Disorder in Young Children: A Systematic Evidence Review for the U.S. Preventive Services Task Force. AHRQ Publ No 13-05185-EF-1 [Internet]. 2015;(121):202. Available from: http://www.ncbi.nlm.nih.gov/pubmed/ $26985520 \% 5 \mathrm{Cnhttp}: / /$ w w w. uspreventive servicestaskforce.org/Page/Document/draft-evidencereview106/autism-spectrum-disorder-in-young-childrenscreening

37. Filipek PA, Accardo PJ, Ashwal S, Baranek GT, Cook EH, Dawson G, et al. Practice parameter: Screening and diagnosis of autism. Report of the quality standards subcommittee of the American Academy of Neurology and the Child Neurology Society. Neurology. 2000; 55(4): 468-79.

38. Wijeratne M, Seneviratne R, Gunawardena N, Østbye T, Lynch C, Sandøy IF. Development of the Sri Lankan early teenagers' violence inventory: An instrument to measure peer violence in schools. Biomed Res Int. 2014; 2014.

39. Friedman-Weieneth JL, Doctoroff GL, Harvey EA, Goldstein LH. The disruptive behavior rating scale-parent version (DBRS-PV): Factor analytic structure and validity among young preschool children. J Atten Disord. 2009; 13(1): 42-55.

40. Mallawaarachchi BC. Disruptive behaviour disorders among adolescents of 11 to 17 years in the Galle district: validation of a study instrument and assessment of prevelence and risk factors. Available from: http:// librepository.pgim.cmb.ac.lk

41. Johnston LD, O’Malley PM. Issues of validity and population coverage in student surveys of drug use. NIDA Res Monogr. 1985; 57: 31-54.

42. Self-report methods of estimating drug use: Meeting current challenges to validity. NIDA Res Monogr. 1985; 57.

43. Ismail AC, Seneviratne RDA. Adaptation and validation of a self-report measure to evaluate substance use among Sri Lankan adolescents. Subst Use Misuse. 2010; 45(12): 213-23.

44. Fekkes M, Theunissen NCM, Brugman E, Veen S, Verrips EGH, Koopman HM, et al. Development and psychometric evaluation of the TAPQOL: A health-related quality of life instrument for 1-5-year-old children. Qual Life Res. 2000; 9(8): 961-72.

45. Jayakody H, Senarath U, Attygalle D. Health related quality of life instrument for preschool aged children in Sri Lanka: validation study. J Postgrad Inst Med. 2018; 5(1): 62.

46. Zolotor AJ, Runyan DK, Dunne MP, Jain D, Péturs HR, Ramirez C, et al. ISPCAN Child Abuse Screening Tool Children's Version (ICAST-C): Instrument development and multi-national pilot testing. Child Abus Negl. 2009;33(11):833-41.
47. Chandraratne NK, Fernando AD, Gunawardena N. Cultural adaptation, translation and validation of the ISPCAN Child Abuse Screening Too - Retrospective Version (ICAST-R) for young adults in Sri Lanka. Child Abus Negl. 2018; 84: 11-22.

48. Shoeb M, Weinstein H, Mollica R. The Harvard trauma questionnaire: Adapting a cross-cultural instrument for measuring torture, trauma and posttraumatic stress disorder in Iraqi refugees. Int J Soc Psychiatry. 2007; 53(5): 447-63.

49. Tay AK, Jayasuriya R, Jayasuriya D, Silove D. Assessing the factorial structure and measurement invariance of PTSD by gender and ethnic groups in Sri Lanka: An analysis of the modified Harvard Trauma Questionnaire (HTQ). J Anxiety Disord. 2017; 47: 45-53.

50. George M. Sri Lankan Tamil diaspora: Contextualizing pre-migration and post-migration traumatic events and psychological distress [Internet]. ProQuest Dissertations and Theses. 2009. Available from: http://search. proquest.com/docview/577358272?accountid= 14553\%5Cnhttp://openurl.library.uiuc.edu/ sfxlcl3?url_ver=Z39.88-2004\&rft_val_fmt=info:ofi/fmt: kev:mtx:dissertation \&genre=dissertations $+\&+$ theses \&sid= ProQ:ProQuest+Dissertations+\&+Theses+Full+Text\&atitl

51. Sullivan MJ. https://sullivan-painresearch.mcgill.ca/pdf/ pcs/PCSManual_English.pdf. 1995.

52. Pallegama RW, Ariyawardana A, Ranasinghe AW, Sitheeque M, Glaros AG, Dissanayake WP, et al. The Sinhala Version of the Pain Catastrophizing Scale: Validation and Establishment of the Factor Structure in Pain Patients and Healthy Adults. Pain Med (United States). 2014; 15(10): 1734-42.

53. Melzack R. The short-form McGill pain questionnaire. Pain. 1987; 30(2): 191-7.

54. Edirisinghe NP, Makuloluwa TR, Amarasekara TD, Goonewardena CSE. Psychometric properties of Sinhala version of short-form mcgill pain questionnaire-2 (sf mpq2-sin) among patients with cancer pain in Sri Lanka. Pain Res Manag. 2019; 2019.

55. Buysse DJ, Reynolds CF, Monk TH, Berman SR, Kupfer DJ. The Pittsburgh sleep quality index: A new instrument for psychiatric practice and research. Psychiatry Res. 1989; 28(2): 193-213.

56. Anandakumar D, Dayabandara M, Ratnatunga SS, Hanwella R, de Silva VA. Validation of the Sinhala version of the Pittsburgh Sleep Quality Index. Ceylon Med J. 2016; 61(1): 22-5.

57. Doneh B. Epworth sleepiness scale. Vol. 65, Occupational Medicine. 2015. p. 508.

58. Krishnamoorthy Y, Sarveswaran G, Sakthivel M, Kalaiselvy A, Majella MG, Lakshminarayanan S. Construct validation and reliability assessment of Tamil version of epworth sleepiness scale to evaluate daytime sleepiness among adolescents in rural Puducherry, South India. J Neurosci Rural Pract. 2019; 10(1): 89-93.

59. Topp CW, Ostergaard SD. The WHO-5 well-being index: A systematic review of the literature. Psychother Psychosom. 2015; 
60. Perera BPR, Jayasuriya R, Caldera A, Wickremasinghe AR. Assessing mental well-being in a Sinhala speaking Sri Lankan population: Validation of the WHO-5 well-being index. Health Qual Life Outcomes. 2020; 18(1).

61. World Health Organization. WHO Disability Assessment Schedule 2.0 (WHODAS 2.0). WHO. 2018.

62. Wijesekara HMADM, Jayawardana P, Fernando PLN. Psychometric properties of the World Health Organization Disability Assessment Schedule 2.0, the proxy version for assessment of disability among schizophrenic individuals. J Coll Community Physicians Sri Lanka. 2016; 22(1).

63. Krupat E, Yeager CM, Putnam S. Patient role orientations, doctor-patient fit, and visit satisfaction. Psychol Heal. 2000; 15(5): 707-19.

64. Mudiyanse RM, Pallegama RW, Jayalath T, Dharmaratne S, Krupat E. Translation and validation of patientpractitioner orientation scale in Sri Lanka. Educ Heal Chang Learn Pract. 2015; 28(1): 35-40.

65. Wijegoonewardene N, Vidanapathirana J, Fernando T. Validation of the Maslach Burnout Inventory - Human Services Survey to assess burnout of prison officers working in Sri Lankan Prisons. J Coll Community Physicians Sri Lanka. 2019; 25(1): 15.

66. Walker SN, Sechrist KR, Pender NJ. The health-promoting lifestyle profile: Development and psychometric characteristics. Nurs Res. 1987; 36(2): 76-81.

67. Rathnayake N, Alwis G, Lenora J, Lekamwasam S. Applicability of health promoting lifestyle profile-II for postmenopausal women in Sri Lanka; A validation study. Health Qual Life Outcomes. 2020; 18(1).

68. Morisky DE, Ang A, Krousel-Wood M, Ward HJ. Predictive validity of a medication adherence measure in an outpatient setting. J Clin Hypertens. 2008; 10(5): 34854.

69. Mannapperuma U, Galappatthy P, De Silva VA, Hanwella R, Jayakody RL, Morisky DE. Validation of the Sinhala version of the Morisky Medication Adherence Scale to determine medication adherence in patients with bipolar affective disorder on lithium therapy. Eur J Pers Centered Healthc. 2018; 6(1): 30.

70. Edition TM, Gignac GE, D P. Genos Emotional Intelligence Inventory. Interpreting. 2019; 409-12.

71. Edussuriya D, Tennakoon SUB, Marambe KN, Rathnayake RMISD, Premaratne BG, Ubhayasiri SK. Translation and validation of the genos emotional intelligence inventory (concise version) for use in Sri Lanka. Sri Lanka J Med. 2017; 26(1): 20.

72. Janssen E, Vorst H, Finn P, Bancroft J. The sexual inhibition (SIS) and sexual excitation (SES) scales: I. Measuring sexual inhibition and excitation proneness in men. J Sex Res. 2002; 39(2): 114-26.

73. Quinta Gomes AL, Janssen E, Santos-Iglesias P, PintoGouveia J, Fonseca LM, Nobre PJ. Validation of the Sexual Inhibition and Sexual Excitation Scales (SIS/SES) in Portugal: Assessing Gender Differences and Predictors of Sexual Functioning. Arch Sex Behav. 2018; 47(6): 1721-32.

74. The development and validity of the medical student stressor questionnaire (MSSQ). ASEAN J Psychiatry. 2010; 11(1): 13-24.

75. Jayarajah U, Lakmal K, Athapathu A, Jayawardena AJ, de Silva V. Validating the Medical Students' Stressor Questionnaire (MSSQ) from a Sri Lankan medical faculty. J Taibah Univ Med Sci. 2020; 5(5): 344-50.

76. Gupta S, Choudhury S, Das M, Mondol A, Pradhan R. Factors causing stress among students of a medical college in Kolkata, India. Educ Heal Chang Learn Pract. 2015; 28(1): 92-5.

77. Abeyasinghe DRR, Tennakoon S, Rajapakse TN. The development and validation of the Peradeniya Depression Scale (PDS) - A culturally relevant tool for screening of depression in Sri Lanka. J Affect Disord. 2012; 142(1-3): 143-9. 